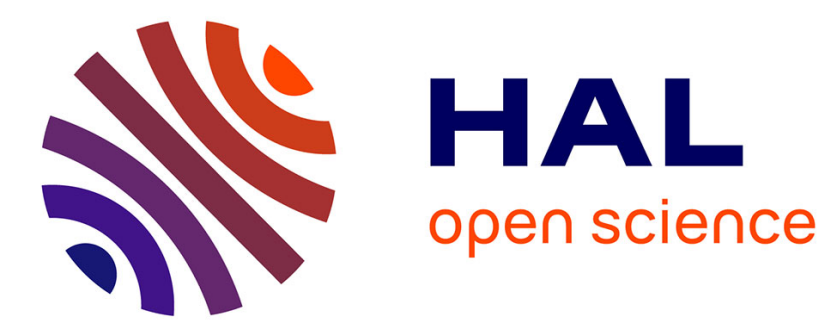

\title{
Microstructural refinement and superplasticity of IN-718 superalloy
}

\author{
L. Ceschini, G. Cammarota, G. Garagnani, A. Africantov
}

\section{To cite this version:}

L. Ceschini, G. Cammarota, G. Garagnani, A. Africantov. Microstructural refinement and superplasticity of IN-718 superalloy. Journal de Physique IV Proceedings, 1993, 03 (C7), pp.C7-335-C7-338. 10.1051/jp4:1993750 . jpa-00252168

\section{HAL Id: jpa-00252168 https://hal.science/jpa-00252168}

Submitted on 1 Jan 1993

HAL is a multi-disciplinary open access archive for the deposit and dissemination of scientific research documents, whether they are published or not. The documents may come from teaching and research institutions in France or abroad, or from public or private research centers.
L'archive ouverte pluridisciplinaire HAL, est destinée au dépôt et à la diffusion de documents scientifiques de niveau recherche, publiés ou non, émanant des établissements d'enseignement et de recherche français ou étrangers, des laboratoires publics ou privés. 


\title{
Microstructural refinement and superplasticity of IN-718 superalloy
}

\author{
L. CESCHINI, G.P. CAMMAROTA, G.L. GARAGNANI and A. AFRICANTOV* \\ Istituto di Metallurgia, Università di Bologna, Italy \\ * Moscow Steel and Alloys Institute, Moscow 117936, Russia
}

\begin{abstract}
A new thermal and mechanical treatment, based on a cold-work cycle, able to promote a superplastic behaviour in the IN-718 superalloy is illustrated. The optimum conditions of temperature and strain rate for the best superplastic behaviour of the alloy have been found. The influence of microstructural parameters and the mechanisms involved during the deformation process are discussed through examination of the flow curves at various temperatures and strain rates, and by metallographic analyses.
\end{abstract}

\section{INTRODUCTION}

Nickel-iron based superalloys, such as IN-718, are being widely used for their good strength, corrosion resistance and weldability as well as for their long-time stability below $650{ }^{\circ} \mathrm{C}$. Further improvement in these properties could be achieved by promoting superplastic behaviour for applications in superplastic forming technologies. For this approach to be successful the alloy must, first of all, be specially processed to induce small grain sizes $(\mathrm{d} \leq 10 \mu \mathrm{m})$ stable at high forming temperatures, and therefore the optimum conditions for superplastic deformation must be found. This study was carried out on wrought $\mathbb{I N}-718$ superalloy with the following aims: to find a processing route, based on a cold-work cycle, to produce a fine-grained two-phase microstructure; to determine the optimum range of temperature and strain rate for the best superplastic behaviour of the alloy; and to evaluate the influence of microstructural parameters, such as grain size and volume fractions of the phases, on the superplastic properties.

\section{EXPERIMENTAL PROCEDURE}

The processing route followed for grain refinement of the wrought IN-718 superalloy consists of the following main steps: (a) solution treatment at $1040^{\circ} \mathrm{C}$ for 1 hour and water quenching; (b) cold rolling with $80 \%$ thickness reduction; and (c) recrystallization annealing at $940{ }^{\circ} \mathrm{C}$ for 1 hour. The superplastic behaviour of the alloy was studied by uniaxial tensile tests carried out on flat specimens (10 mm gauge length, $5 \mathrm{~mm}$ gauge width, $2 \mathrm{~mm}$ thickness) machined from the as-rolled sheets with the tensile axes along the rolling direction. The specimens were used in the as-rolled conditions, without any recrystallization annealing before the tensile tests, because the heavily deformed microstructure recrystallizes dynamically during superplastic flow. Tensile tests were carried out at different initial strain rates, ranging from $2.42 \cdot 10^{-4} \mathrm{~s}^{-1}$ to $4.8 \cdot 10^{-3} \mathrm{~s}^{-1}$ and at temperatures between $900^{\circ} \mathrm{C}$ and $980^{\circ} \mathrm{C}$. The strain-rate sensitivity, 
$m$, was determined by step strain-rate tests. Microstructural characterizations were made by means of optical and electron microscopy (SEM and TEM), EDS analysis and X-ray diffraction analysis.

\section{RESULTS AND DISCUSSION}

The first objective of this work was to produce sheets from wrought IN-718 alloy with a fine-grained double-phase microstructure stable at the deformation temperature. In the as-received condition the alloy consisted of a $\gamma$ austenitic matrix (grain size $>100 \mu \mathrm{m}$ ) with MC carbides (usually Ti or $\mathrm{Nb}$ carbides) and low precipitation at the grain boundaries of the $\gamma^{\prime \prime}$ phase, a metastable coherent precipitate having a stoichiometry based on $\mathrm{Ni}_{3} \mathrm{Nb}(\mathrm{Al}, \mathrm{Ti})$. The processing route, based on a cold-work cycle, was able to produce a fine-grained microstructure with $\gamma$ and $\delta$ phases. The $\delta$ phase is a stable incoherent precipitate having a stoichiometry based on $\mathrm{Ni}_{3} \mathrm{Nb}$.

The solution treatment at $1040^{\circ} \mathrm{C}$ for 1 hour produced an austenitic matrix with all the elements in solution except the $\mathrm{Ti}, \mathrm{Nb}$ and $\mathrm{C}$ in the carbides. The subsequent cold rolling led to heavily deformed zones with a high dislocation density and lattice misorientations, which provided a considerable driving force for recrystallization. The successive annealing treatment of the cold-rolled alloy, in the temperature range between 900 and $980^{\circ} \mathrm{C}$, produced very fine grain sizes (ranging from about 1 to $10 \mu \mathrm{m}$ ) and varying proportions of the $\gamma$ and $\delta$ phases, ranging from about $50 \% \gamma$ and $50 \% \delta$ at $940{ }^{\circ} \mathrm{C}$ to a pseudo-monophasic composition at $980^{\circ} \mathrm{C}$ (Fig.1). The nature of the second phase was confirmed by SEM and TEM analyses (Fig.2) as well as by X-ray diffraction analysis [1]. The behaviour of the $\delta$ phase in a high working temperature regime is an important concern during superplastic deformation. Indeed if insufficient $\delta$ phase is present during high temperature deformation, then grain boundary pinning may be inadequate, resulting in a high level of grain growth.

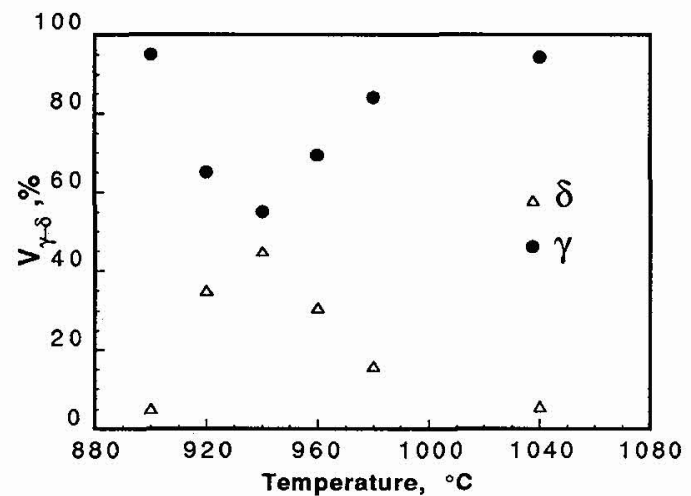

Eig.1: Volume fractions of the $\gamma$ and $\delta$ phases after annealing for 1 hour at various temperatures.

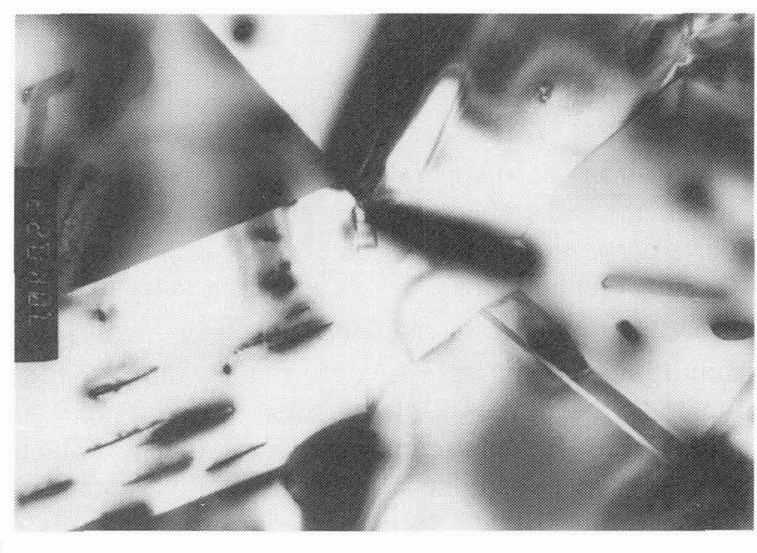

Fig.2: TEM micrograph of the IN-718 alloy annealed at $940{ }^{\circ} \mathrm{C}$ for 1 hour : $\gamma$ and $\delta$ phases, with carbides (17000X).

The second objective of the research was to test the superplasticity of the IN-718 alloy and to develop a knowledge of the deformation mechanisms involved. In order to determine the optimum temperature and strain rate for the superplastic deformation, tensile tests in the temperature range between 900 and $9800^{\circ} \mathrm{C}$ with initial strain rates from $2.42 \cdot 10^{-4} \mathrm{~s}^{-1}$ to $4.8 \cdot 10^{-3} \mathrm{~s}^{-1}$ were carried out. The results, shown in Fig.3, indicate that, for all the testing conditions, elongations to failure were always greater than $300 \%$, indicating high levels of superplastic properties of the alloy. The maximum elongation, $\delta=1050 \%$, was measured in the specimen deformed at $920^{\circ} \mathrm{C}$ with an initial strain rate of $9.68 \cdot 10^{-4} \mathrm{~s}^{-1}$. The curves in Fig.3 also show that an increase in strain rate shifts the maximum elongation to the lower temperature. This trend is opposite 
to that of usual superplastic behaviour, with grain boundary sliding being the main mechanism of deformation, when higher temperatures allow the use of higher strain rates. The trend observed may be explained by means of the dynamic recrystallization of the alloy.

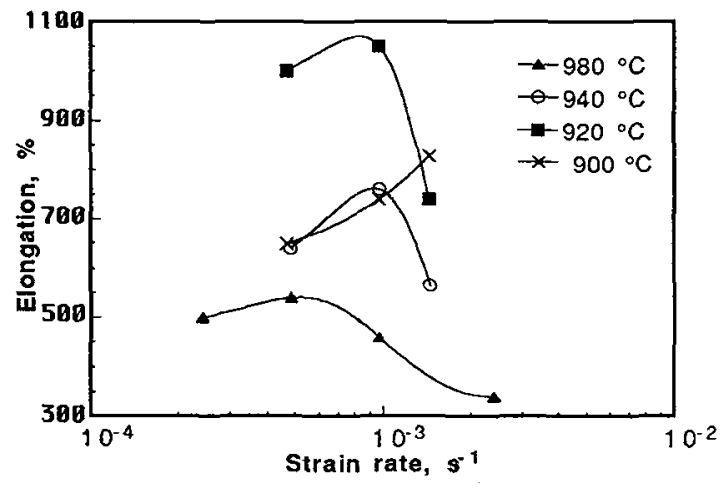

Fig.3: Elongation to failure as a function of strain rate at various temperatures.

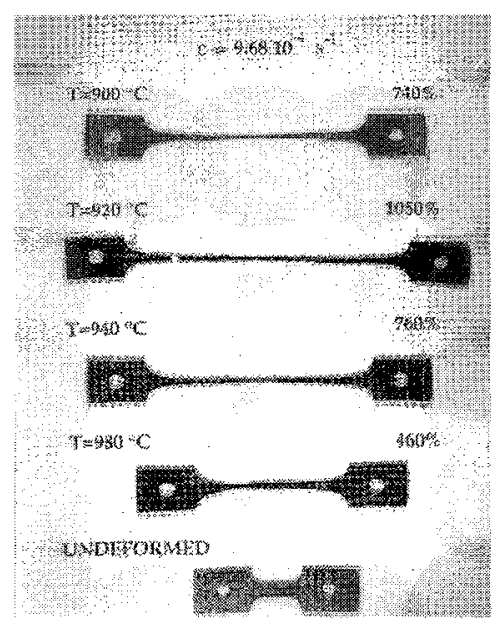

Fig.4: Tensile specimens of IN-718 alloy deformed at various temperatures with an initial strain rate of $9.68 \cdot 10^{-4} \mathrm{~s}^{-1}$.

One of the main characteristics of flow curves associated with dynamic recrystallization is the occurrence of a peak, followed by a decreasing flow stress. The strain at peak stress $\varepsilon_{\mathrm{p}}$ gives some indication of the critical strain required for the occurence of recrystallization. The flow curves, for tensile tests carried out at different temperatures with an initial strain rate of $9.68 \cdot 10^{-4} \mathrm{~s}^{-1}$, are reported in Fig.5. The curves at 980 , 940 and $900^{\circ} \mathrm{C}$ show that a decrease in temperature produces an increase in flow stress and a decrease in the strain associated with the peak stress $\left(\varepsilon_{\mathrm{p}}\right.$ ranges from about 0.8 at $980{ }^{\circ} \mathrm{C}$ to 0.5 at $900{ }^{\circ} \mathrm{C}$ ). The specimen tested at $920^{\circ} \mathrm{C}$ showed the highest elongation with low stress after the lowest strain value $\left(\varepsilon_{p}=0.2\right)$. At this temperature the flow curve exhibited an extensive stress-plateau region, characteristic of considerable superplastic deformation. This steady-state region may well be explained as being a result of subgrain formation with successive local formation of high-angle boundaries.

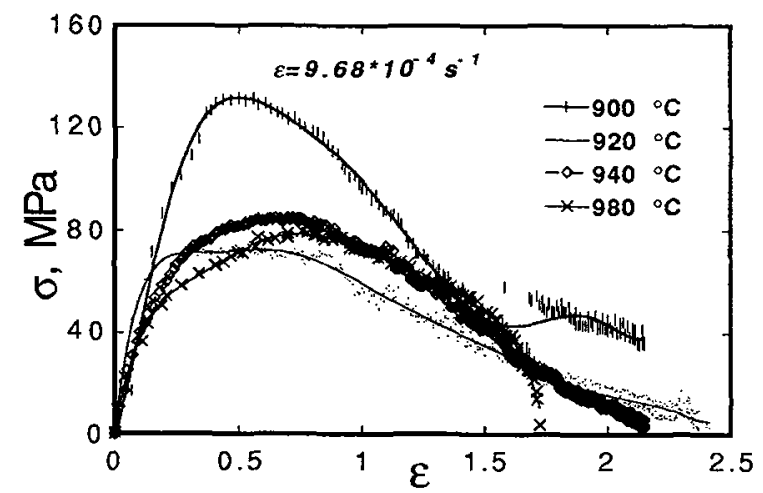

Fig.5: Effect of temperature on the flow curves of specimens deformed at a strain-rate of $9.68 \cdot 10^{-4} \mathrm{~s}^{-1}$.
The variation in flow stress with strain rate at various temperatures, obtained from step strain-rate tests, is illustrated in Fig.6-a. For strain rates up to $1.5 \cdot 10^{-4} \mathrm{~s}^{-1}$ the flow stress always decreases with increasing temperatures. In the strain rate range from $1.5 \cdot 10^{-4} \mathrm{~s}^{-1}$ to $9.6 \cdot 10^{-4} \mathrm{~s}^{-1}$, the flow stress at $980{ }^{\circ} \mathrm{C}$ is higher than at $940{ }^{\circ} \mathrm{C}$ probably because of the grain growth at the higher temperature. Similar behaviour is observed for strain rates higher than $1.6 \cdot 10^{-3} \mathrm{~s}^{-1}$ when

the flow stress at $920^{\circ} \mathrm{C}$ is lower than at 940 ${ }^{\circ} \mathrm{C}$. For all the test temperatures, especially in the range $920-980^{\circ} \mathrm{C}$, the values of flow 
stress differ slightly; this is useful for superplastic forming of large components, when temperature gradients in the die always occur.

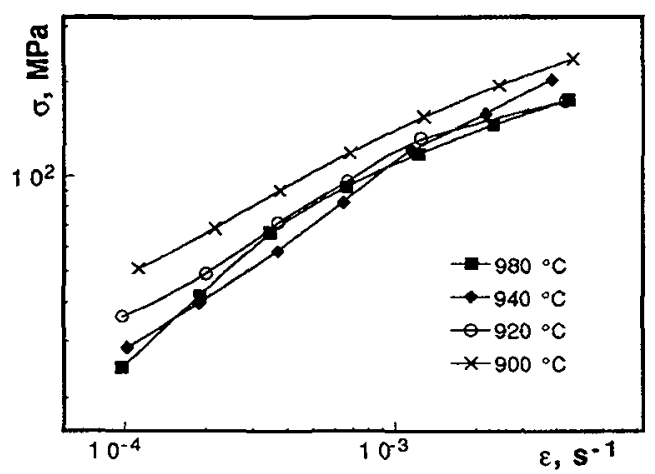

Fig.6-a: Flow stress as a function of strainrate at various temperatures.

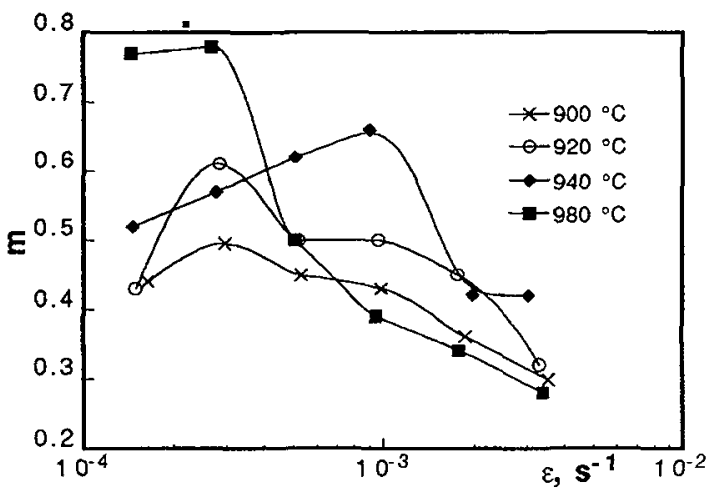

Fig.6-b: $\quad m$-values as a function of strain-rate at various temperatures.

The $m$-values were determined from the slope of the true stress and true strain-rate curves (Fig.6-b). In all the testing conditions the strain-rate sensitivity $m$ is higher than 0.3 , thus confirming typical superplastic behaviour. The variations in the index $\mathrm{m}$ strictly depend on the evolution of the microstructure during deformation, which consists of grain growth and grain refinement. The range of strain rate in which one or the other of these microstructural processes are more effective can be derived from the plots of Fig.6-b. For strain rates lower than about $4 \cdot 10^{-4} \mathrm{~s}^{-1}$, due to grain growth the values of the maximum $\mathrm{m}$ increase with increasing temperature, except that at $940^{\circ} \mathrm{C}$. At higher strain rates another maximum in $\mathrm{m}$ occurs due to grain refinement during dynamic recrystallization. This behaviour corresponds to the model of the evolution of grain size distribution during superplastic deformation proposed by A.K.Ghosh and R.Raj [2]. The model is based on the simple assumption that regions deforming by diffusional creep, with low strain rates,

suffer strain induced grain growth ( $\dot{\varepsilon}=\sigma / L^{3}$, where $\mathrm{L}$ is the grain size); on the contrary those deformed by power-law creep, with a high strain rate, undergo grain refinement during dynamic recrystallization, by the nucleation and growth of new grains at the interfaces $\left(\varepsilon=\sigma^{n}\right)$. Since diffusional creep is grain-size dependent, because grain growth at the low strain rates appears as a natural consequence of accomodation for grain boundary sliding, and power-law creep is not grain-size dependent, there is a transition from a power-law to diffusional-creep mechanism for a strain rate value which is a function of the grain size. In our case this transition takes place at a strain rate in the range from about $4 \cdot 10^{-4}$ to $5 \cdot 10^{-4} \mathrm{~s}^{-1}$. As a consequence of this model, the highest elongation to failure $\delta=1050 \%$ obtained at $920^{\circ} \mathrm{C}$ for a strain rate of $9.68 \cdot 10^{-4} \mathrm{~s}^{-1}$, with a relatively low value of $m(0.5)$, is a result of the main mechanism of deformation being controlled by dislocation creep. The main role of this mechanism during superplastic deformation of many nickel-based alloys has also been reported in the literature [3].

\section{REFERENCES}

[1] CESCHINI L., CAMMAROTA G.P., GARAGNANI G.L., AFRIKANTOV A., Proceedings of the "14 Convegno nazionale trattamenti termici", AIM Milano (1993) 29

[2] GHOSH A.K., RAJ R., Superplasticité, Ed. B.Baudelet and M.Suery, CNRS Paris (1985) 11

[3] MERRICK H.F., Superplastic forming of structural alloys, Ed. N.E.Paton and C.H.Hamilton, TMSAIME Warrendale (1982) 209. 